\title{
The mass stiffness of residual dolomite from large surcharge trials
}

\author{
S. W. Jacobsz \\ Department of Civil Engineering, University of Pretoria, University Avenue, Pretoria, Gauteng 0002, South Africa
}

(e-mail: sw.jacobsz@up.ac.za)

\begin{abstract}
In South Africa, the stiffness of dolomite residuum has traditionally been viewed as relatively low. For reasons of economy, available dolomite residuum stiffness data mostly stem from plate load tests on each of the materials forming the residual profile, typically chert gravels and wad, rather than on the actual mix of materials that typically occurs in situ. This paper presents back-calculated stiffness values from a series of large-scale surcharge trials carried out in Centurion, south of Pretoria, for the Gautrain Rapid Rail Project. It is shown that the mass stiffness of the residual dolomite profile is significantly higher than the traditionally recognized values of its constituents, allowing the viaducts for the Gautrain south of Pretoria to be founded on dolomite residuum instead of bedrock.
\end{abstract}

In the Centurion area south of Pretoria, the Gautrain railway line, linking the cities of Pretoria and Johannesburg, crosses the Malmani dolomites of the Transvaal Supergroup (see, e.g. Johnson et al. 2006). It was decided to construct the Centurion section on a $c$. $3 \mathrm{~km}$ long viaduct supported on about 70 piers, generally spaced $44 \mathrm{~m}$ apart. The pier heights vary, but are approximately $12 \mathrm{~m}$. A typical pier dead load is $c .30000 \mathrm{kN}$. The contractor was faced with the problem of constructing the viaduct foundation on or in a dolomitic profile and proposed at tender stage to found the viaduct piers on groups of large diameter $(1.5 \mathrm{~m})$ piles end-bearing on dolomite bedrock. Owing to the difficulties associated with constructing piles end-bearing on the highly irregular dolomite bedrock surface, other foundation solutions, avoiding piling to rock, were considered. This meant that foundations had to be founded in or on the residual or transported materials above bedrock, which traditionally had been assumed to be highly compressible and prone to the formation of sinkholes.

A series of large-scale surcharge trials, designed to quantify the mass stiffness of the soil profile above bedrock, were carried out. The surcharge trials, observed settlements, analysis of results and the back-calculated stiffness values are presented in this paper.

\section{Geology and ground profile}

South of Pretoria, travelling in a northerly direction, the Gautrain track alignment crosses respectively the Oaktree, Monté Christo, Lyttleton and Eccles formations of the Malmani Subgroup of dolomites of the Transvaal Basin. The dolomites have ages of c. $2500 \mathrm{Ma}$ (Johnson et al. 2006) and have, as a consequence, weathered dramatically along joint planes, leaving a karst bedrock topography with deep gullies or trenches, flanked by dolomite rock pinnacles. The dolomite bedrock is typically interbedded with chert, shale and quartzite, the quantities of which vary between the various formations. The gullies in the bedrock are often filled with unconsolidated weathering products comprising chert fragments from sand to boulder sizes and highly variable proportions of manganiferous earth (wad), which is highly erodible. The weathering products can also occur as an overburden above the rock head. Cavities, ranging from very small up to several metres in diameter, can occur.
The residual materials above bedrock usually comprise chert gravels and boulders in a matrix of clayey and silty sands. The residual profile is usually overlain by colluvial deposits ranging in thickness up to about $10 \mathrm{~m}$. Materials generally tend to become more porous and more compressible with depth.

Figure 1 presents two photographs of dolomite bedrock exposed at the Lyttelton quarry in Centurion. It shows a large number of rock pinnacles, apparently randomly distributed, giving an extremely variable rock head surface with steep subvertical slopes. These rock head conditions are likely to be representative of the conditions occurring underneath much of the Centurion viaducts. The situation is further illustrated by a summarized borehole record from viaduct Pier 45 in Figure 2. It presents the soil profiles determined from four percussion boreholes drilled on the centrelines of the proposed pile positions at this pier. It illustrates extreme variability in depth to bedrock over short distances, as well as the presence of large cavities in the rock.

The degree of weathering of the intact dolomite bedrock tends to be minimal. The rock is typically extremely hard and exhibits uniaxial compressive strengths of well above $300 \mathrm{MPa}$ (see, e.g. Wagener 1982).

A major problem associated with the dolomites is the sudden appearance of potentially large sinkholes (sometime tens of metres in diameter) owing to near-surface residual and transported materials eroding into solution cavities in the bedrock. This is especially associated with leaking pipes and water ingress into the ground and is exacerbated by the lowering of the ground water table.

The overall geological profile can be described as extremely heterogeneous in terms of composition, depth to bedrock and engineering properties. The profile is, as a consequence, extremely difficult to characterize for foundation design purposes.

In summary, the ground profile along the viaduct comprised chert gravels and boulders in a matrix of hillwash sand, underlain by a potentially compressible and voided dolomite residuum comprising wad with minor chert (according to borehole logs from the site investigation (Bombela CJV 2007)). An important characteristic of the soil profile is its extreme heterogeneity, as it typically contains numerous chert fragments, ranging from gravels to large boulders in a matrix comprising any material from clay, ranging through silty sands, to gravels and boulders. 

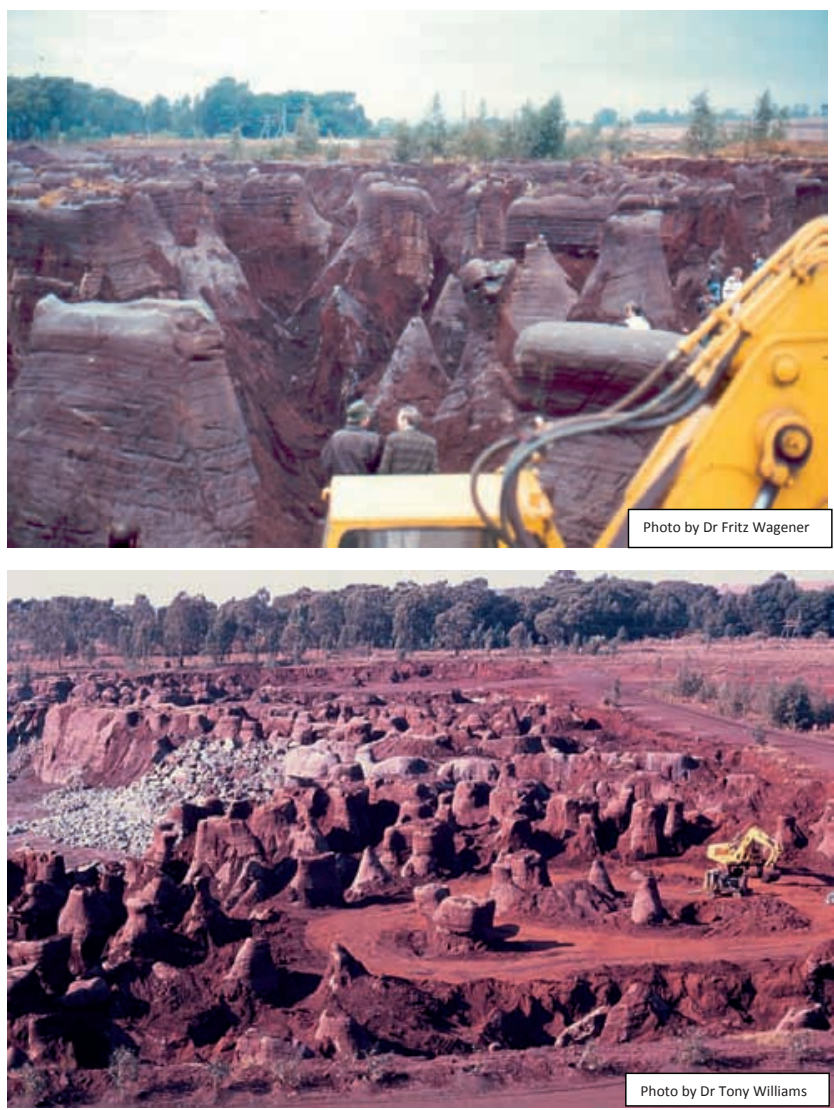

Fig. 1. Dolomite pinnacles exposed in the Lyttelton area.

\section{Difficulties associated with ground investigations}

For the design of a founding solution, the bedrock profile and thickness of the underlying competent rock have to be defined in some detail. This is less problematic in horizontally or subhorizontally bedded profiles, but in the profile described, no economical number of boreholes would allow the bedrock profile to be characterized in sufficient detail to allow a foundation, bearing on bedrock, to be detailed with confidence. Numerous cavities occur in the dolomite bedrock and uncertainty regarding their detection is unavoidable. By means of drilling, only the vertical dimension of a cavity can, at best, be defined. As its lateral extent cannot be defined without drilling numerous boreholes, it is not possible to determine with certainty whether the cavity could be grouted or not. Given the heterogeneity of the dolomite profile, proving an adequate thickness of bedrock below the bases of the proposed piles would have necessitated drilling an investigation hole at every pile position.

The initial ground investigation comprised the drilling of percussion boreholes along the axis of every proposed large diameter pile forming part of the pile groups supporting the viaduct piers. A considerable effort went into the investigation of additional means by which the foundation conditions could be characterized in greater detail. Trials were carried out using various geophysical methods, including borehole radar (see Tosen et al. 2009), but the variability of the bedrock profile was simply too great to be defined in sufficient detail by such methods.

The only way to completely define a bedrock profile in a situation as illustrated in Figure 1 is to expose it, which was not feasible given the thickness of overburden and the number of viaduct piers to construct. (Exposure of the foundation by sinking shaft foundations was selected for some piers, but could not be used at all piers because of the high cost.)

A further complication associated with founding the viaduct on dolomitic bedrock was that, should unsuitable founding conditions (e.g. a large cavern underneath a thin rock cover or excessive depth to competent bedrock) be encountered, it might not have been possible to move the pier in question to suitable founding conditions within the constraints imposed by the viaduct geometry.

This situation led to the conclusion that rock head conditions could not be defined at reasonable cost in sufficient detail to allow pile construction to proceed without considerable risk. A bedrock profile as illustrated in Figure 1, in combination with the fact that the dolomite rock is extremely hard, typically results in serious difficulties during pile installation. Problems are usually revealed only during construction and then have to be dealt with at construction, which is why experienced local geotechnical contractors are hesitant to pile in the dolomites. Thus, consideration of alternative founding solutions was required. Heavy structures such as silos have in the past been founded on residual dolomitic profiles where the foundations did not extend to bedrock (Wagener 1982; Day, pers. comm.). This option was also considered for the Gautrain Viaducts in Centurion. An important issue associated with such a founding solution is the potential settlement of the foundation if placed on the residual soil, and it was therefore necessary to characterize the mass stiffness of the residual dolomite profile.

\section{Existing data on the stiffness of residual dolomite}

A considerable amount of work has been done on the development on dolomitic land since the 1970s (e.g. Wagener 1982; Buttrick 1986). An important aspect in planning construction on residual dolomite is the stiffness of the residual dolomite profile. The bulk of available knowledge regarding the stiffness of residual dolomite profiles stems from plate load tests on the various materials it comprises. However, because of the fact that necessarily small-diameter plate load tests measure stiffness over only a limited depth and typically at relatively large strains, data from such tests are unlikely to be representative of the mass stiffness of the profile as a whole. Typical Young's moduli from plate load tests for chert gravels and wad are presented in Table 1. These values are presented for comparison with the stiffness values that are representative of the overall soil profile later in the paper.

\section{Large-scale surcharge trials}

To assess the mass stiffness of the residual dolomite profile above the dolomite bedrock in response to a typical pier foundation load, a series of large-scale surcharge trials was designed. A typical foundation load would act over an area measuring c. $12 \mathrm{~m} \times 12 \mathrm{~m}$. The in situ mass stiffness of the residual dolomite profile was measured at various locations along the viaduct alignment by loading a similarly large area to average stresses typical of the actual viaduct.

Ward et al. (1968) reported on a similar large-scale surcharge trial where a large cylindrical water-filled tank, measuring $18.3 \mathrm{~m}$ in diameter by $18.3 \mathrm{~m}$ high, was used to exert a bearing stress of $c$. $180 \mathrm{kPa}$ on a chalk foundation in the UK. The test set-up was carefully instrumented to measure surface and subsurface movements in response to the filling of the tank. Closed-form elastic solutions, normally used for the calculation of the Young's modulus from plate load tests, were used to back-calculate soil stiffnesses at various depths below the tank. 

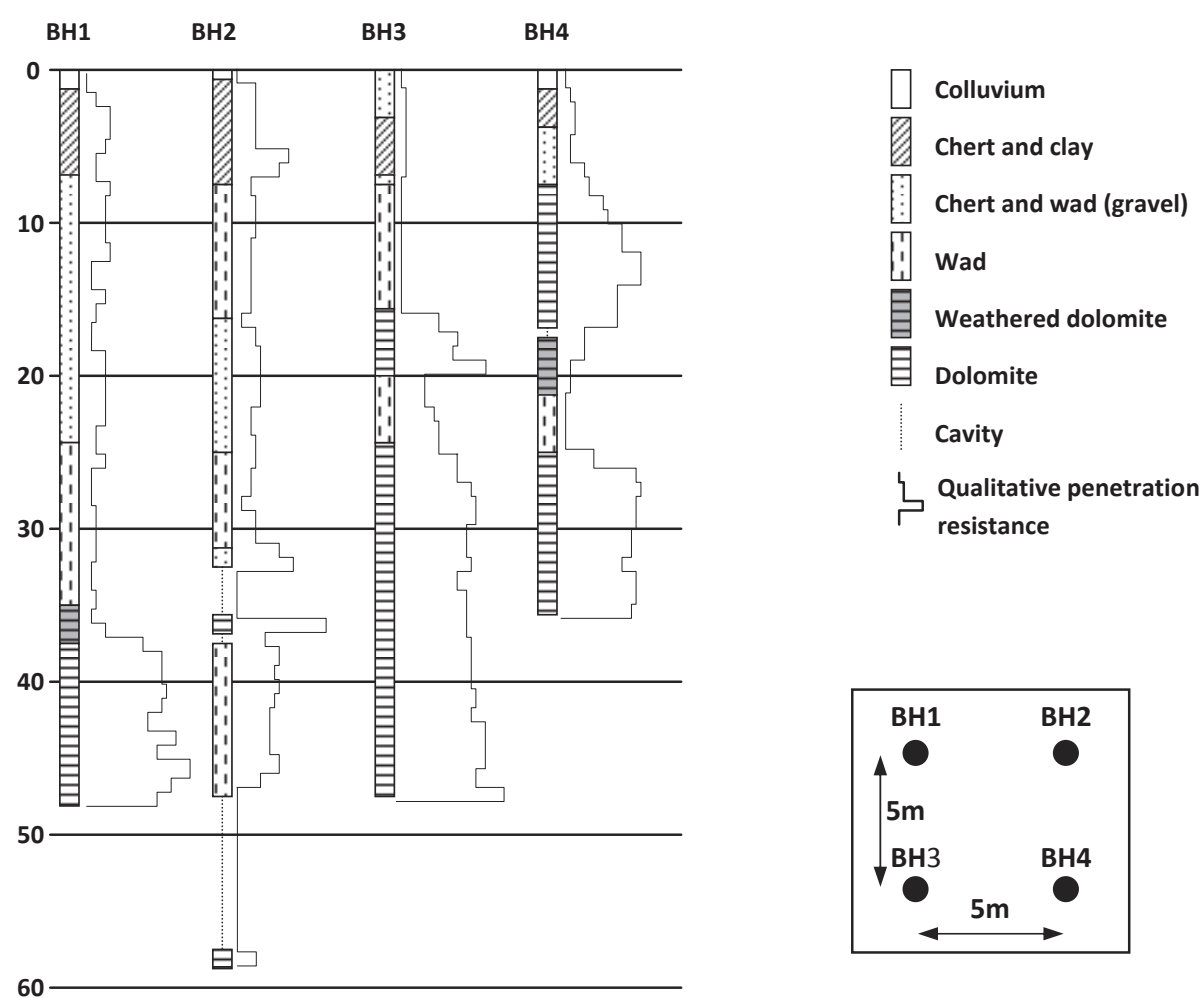

Fig. 2. Borehole profile records from Pier 45 (Bombela CJV 2007).

Table 1. Typical Young's moduli for dolomitic residuum from vertical plate load tests (data from Wagener 1982)

\begin{tabular}{lcccc}
\hline & \multicolumn{3}{c}{ Plate modulus (MPa) } & \multirow{2}{*}{$\begin{array}{c}\text { Number } \\
\text { Material }\end{array}$} \\
\cline { 2 - 4 } & Minimum & Maximum & Average & \\
\hline Chert gravel & 46 & 109 & 80 & 11 \\
Wad & 12 & 22 & 18 & 3 \\
\hline
\end{tabular}

Data from Doringkloof, Centurion. Plate diameter is $1 \mathrm{~m}$.

For the Gautrain project, a surcharge arrangement was required that could be moved relatively easily to many pier locations. The surcharge trials comprised the loading of an area measuring $c$. $20 \mathrm{~m} \times 20 \mathrm{~m}$ as illustrated diagrammatically in Figure 3 . The footprint area of the surcharge was chosen to be larger than the anticipated viaduct pier foundation footprint to ensure than the surcharge would result in effective preloading of all the material at depth within the zone of influence of the foundation. A photograph of the first surcharge trial is presented in Figure 4. The surcharge consisted of $2 \mathrm{~m} \times 2 \mathrm{~m} \times 1 \mathrm{~m}$ high concrete blocks, weighing $c$. 9.6 tons each, stacked to a height of between 8 and $10 \mathrm{~m}$, exerting a vertical stress of up to $240 \mathrm{kPa}$. The blocks were initially placed in four quadrants, separated by $800 \mathrm{~mm}$ wide passages to allow access between the blocks for monitoring purposes. Precise levelling benchmarks were installed at various locations around the surcharge to measure surface settlement (see Fig. 3). The settlement monitoring points were constructed by augering $200 \mathrm{~mm}$ diameter holes to $1 \mathrm{~m}$ and placing $700 \mathrm{~mm}$ of concrete into which roundheaded bolts were inserted as the measuring points. Precast manhole rings were stacked $300 \mathrm{~mm}$ high around each monitoring point to the surface and the ground around each monitoring point was raised somewhat to prevent accumulation of water.

In addition to surface monitoring points, two sets of rod extensometers were installed at the first two surcharge test sites to measure subsurface movements. Because of cost constraints these extensometers were not installed at subsequent test locations.

A concern arose during the stacking of the first surcharge that the surface settlement monitoring points might not accurately reflect the settlement of the concrete blocks themselves owing to the blocks apparently 'sinking' into the ground. The first layer of the surcharge was subsequently modified by stacking the blocks together, removing the access passage at ground level. This was done for all surcharge trials except the first two. Settlement monitoring points were henceforth placed at the same plan locations as before, but bolted to the first layer of blocks so that block settlements and not soil settlements were measured.

Settlements were monitored at four categories of locations. These are the four corners, four at the centre on the inside corners of each quadrant, four at mid-side and four at mid-passage positions (i.e. halfway between the centre and the mid-side positions). The modified surcharge layout is presented in Figure $3 \mathrm{~b}$.

The monitoring points were surveyed by means of precise levelling, generally on a daily basis before and during the stacking of the surcharge. The monitoring frequency was reduced once movements had stabilized.

In addition to serving as a monitoring tool for the determination of the in situ stiffness of the soil profile, the trials also provided a surcharge acting as pre-loading, so that a higher (reload) stiffness would be expected during subsequent foundation loading.

The surcharge trials were carried out at a total of 30 pier locations along the alignment of the Centurion viaduct.

\section{Calculation of profile stiffness from surcharge settlement}

In addition to soil stiffness, the settlement of the surcharge at ground level is affected by several other factors. These include: (1) lateral non-homogeneity of the residual dolomite soil and 
(a)

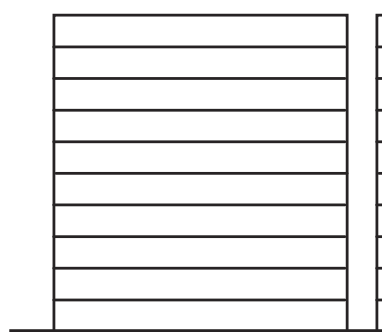

Elevation on first two surcharge trials only.

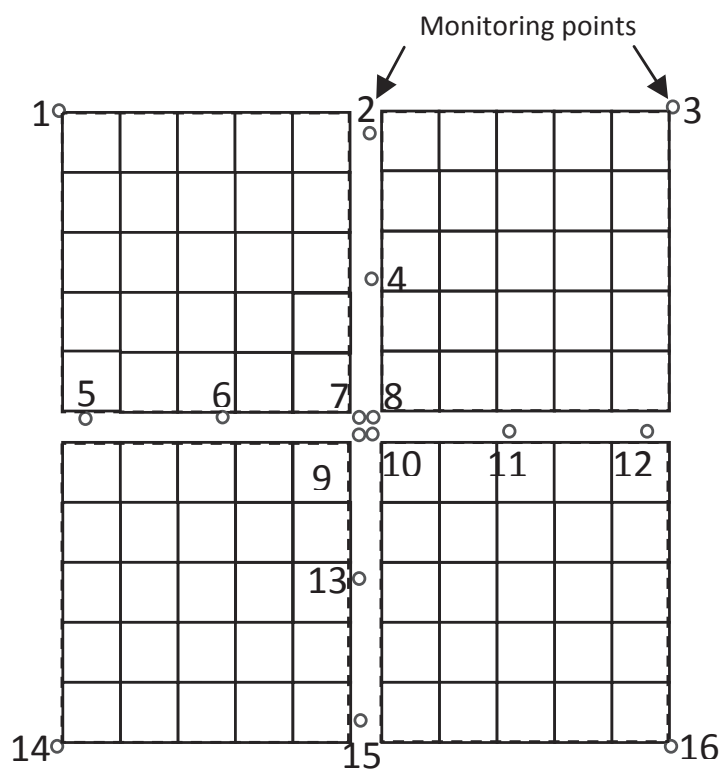

Surcharge stacked in four separate quadrants in first two surcharge trials only. (b)

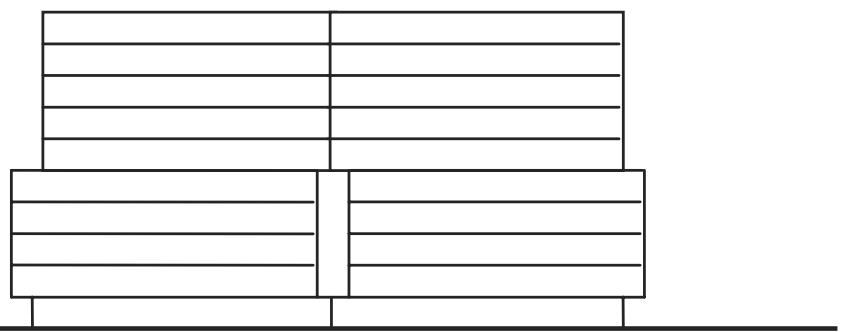

Elevation on surcharge trials, excluding the first two.

Layers 1 and 6 to 10 of surcharge stacked together - no passage.

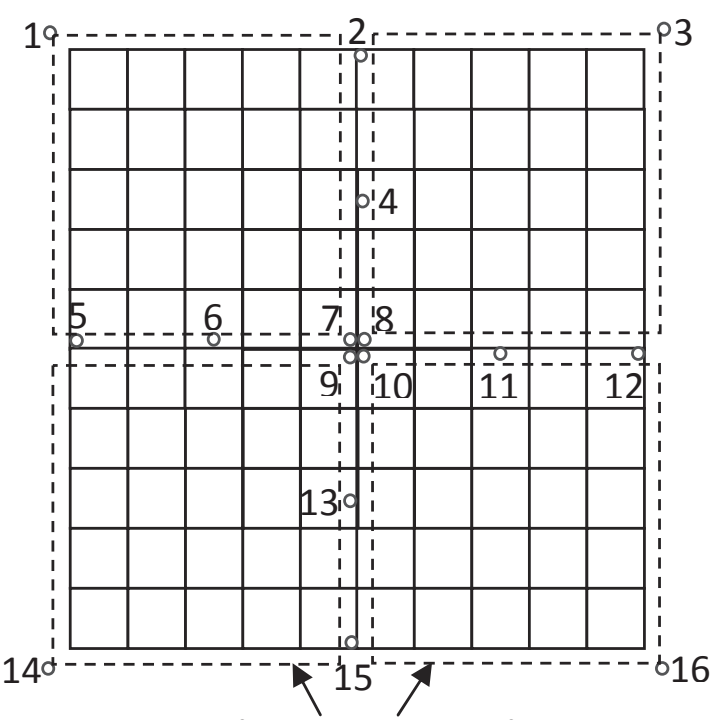

Layers 2 to 5 of surcharge stacked in four separate quadrants to create access for monitoring.

Fig. 3. Elevation and plan views of the two surcharge trial arrangements used.

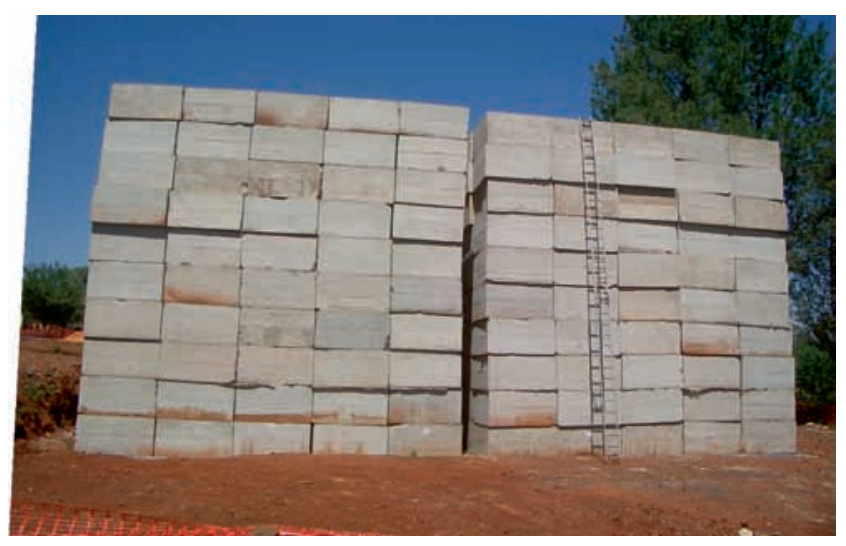

Fig. 4. The first surcharge stack shortly after completion.

bedrock profiles as illustrated in Figures 1 and 2; (2) nonhomogeneity owing to stiffness changes with depth (see, e.g. Gibson 1967, 1974; Rodrigues 1975; Carrier \& Christian 1973); (3) stiffness anisotropy (Rodrigues 1975); (4) the non-linearity in stiffness (see, e.g. Jardine et al. 1986); (5) yielding of the soil in response to the load; (6) the degree of rigidity of the loaded area (see, e.g. Gibson 1974; Boswell \& Scott 1975), etc.

When back-calculating stiffness moduli, most of these factors can be accounted for using a sufficiently sophisticated numerical model, provided the spatial variability of the ground is known or can be reasonably assumed. However, owing to the uncertainty associated with the non-homogeneity of the profile (especially the random distribution of rock pinnacles, boulders, cavities and zones of various consistencies), which could not be determined in sufficient detail to support a comprehensive 3D analysis of each viaduct pier foundation, a simplified approach for back-calculating stiffness moduli was necessary.

A single stiffness value was calculated at each monitoring point by calculating the average stress increase below each point using the Boussinesq vertical stress distribution and dividing that by the average strain at that point. The average strain was calculated by dividing the monitoring point settlement by the average thickness of compressible materials above bedrock at that pier location as determined from the site investigation data. This analysis resulted in the following approximations.

- It disregarded the 3D non-homogeneity of the soil profile, as this could not be captured in detail by the ground investigation.

- It assumed the bedrock profile to be flat at each pier position.

- It ignored contributions from lateral stress effects (Poisson effects).

- It ignored the fact that Boussinesq stress distribution applies to a semi-infinite homogeneous half-space rather than a profile of limited depth.

- It disregarded yielding of the soil. 

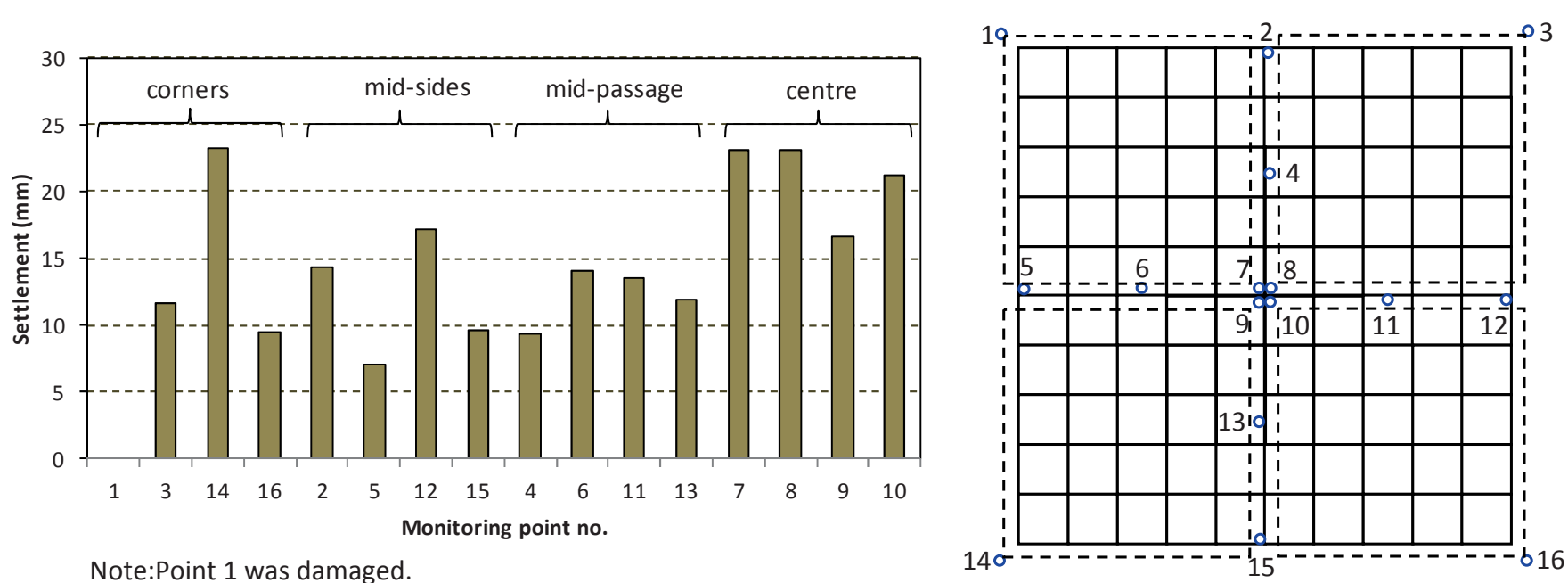

Fig. 8. Distribution of maximum measured settlement on the first layer of blocks at Pier 26.
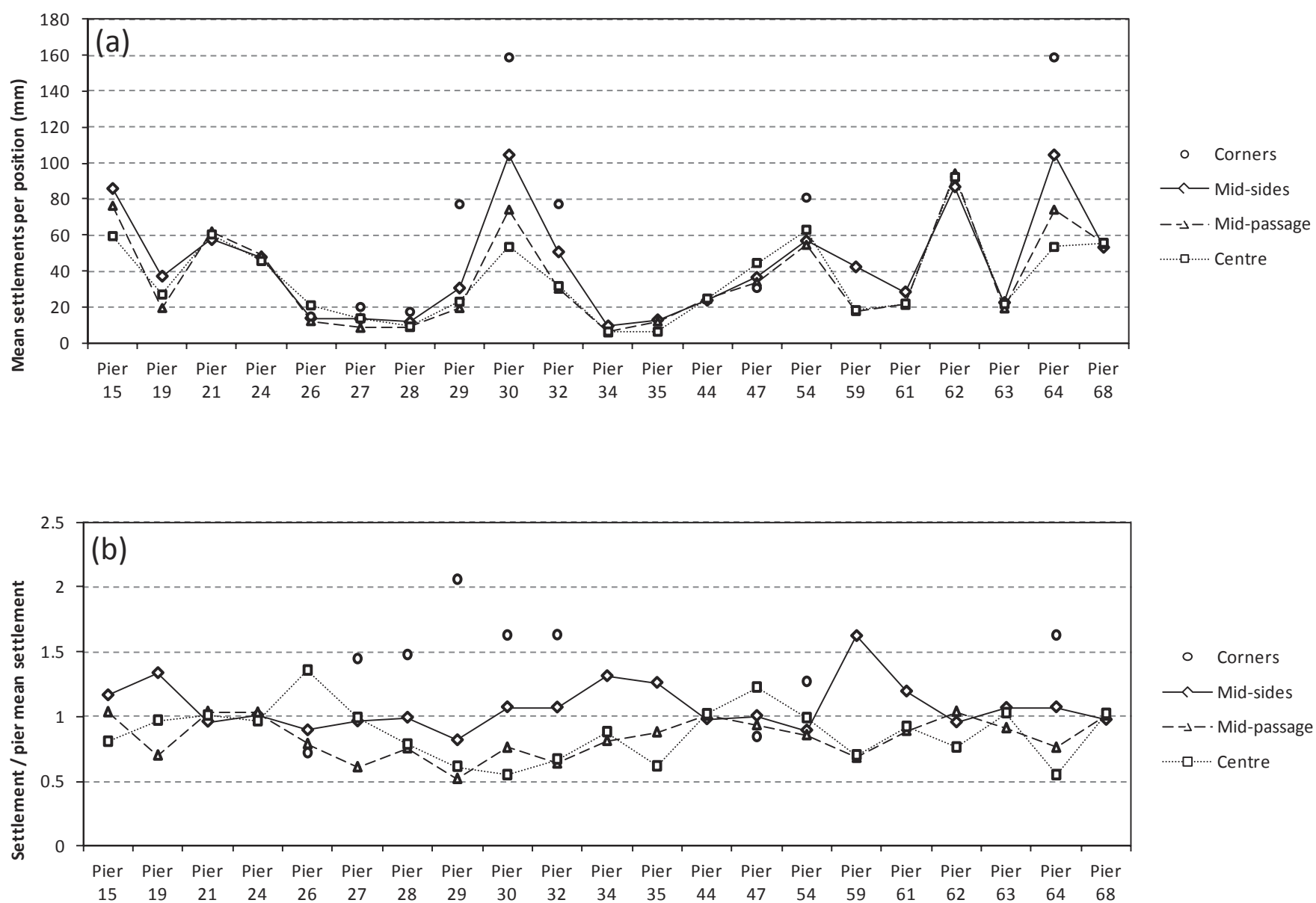

Fig. 9. Actual and normalized settlement of the first layer of blocks at mid-side, mid-passage, centre and corner positions of surcharged piers along the viaduct.

The stiffness data are tabulated in Table 2, presenting the minimum and maximum values per pier, as well as the average values and standard deviations. A log-normal distribution was found to describe the stiffness data relatively well.

Figure 12 illustrates the variation in minimum, average and maximum Young's moduli back-calculated at the various piers graphically and also the variation in average depth to bedrock at each pier. Also shown are typical Young's moduli from plate load tests on chert gravel and wad from Wagener (1982). By plotting average settlement and stiffness against profile depth (Fig. 13a and b), a very weak correlation between the thickness of the compressible soil layer and settlement becomes evident, but virtually no correlation with the back-calculated stiffness is evident.

\section{Rebound stiffnesses}

As illustrated in Figure 6, some rebound took place upon removal of the surcharge. This was considerably less than the settlement that occurred, reflecting the increase in stiffness 

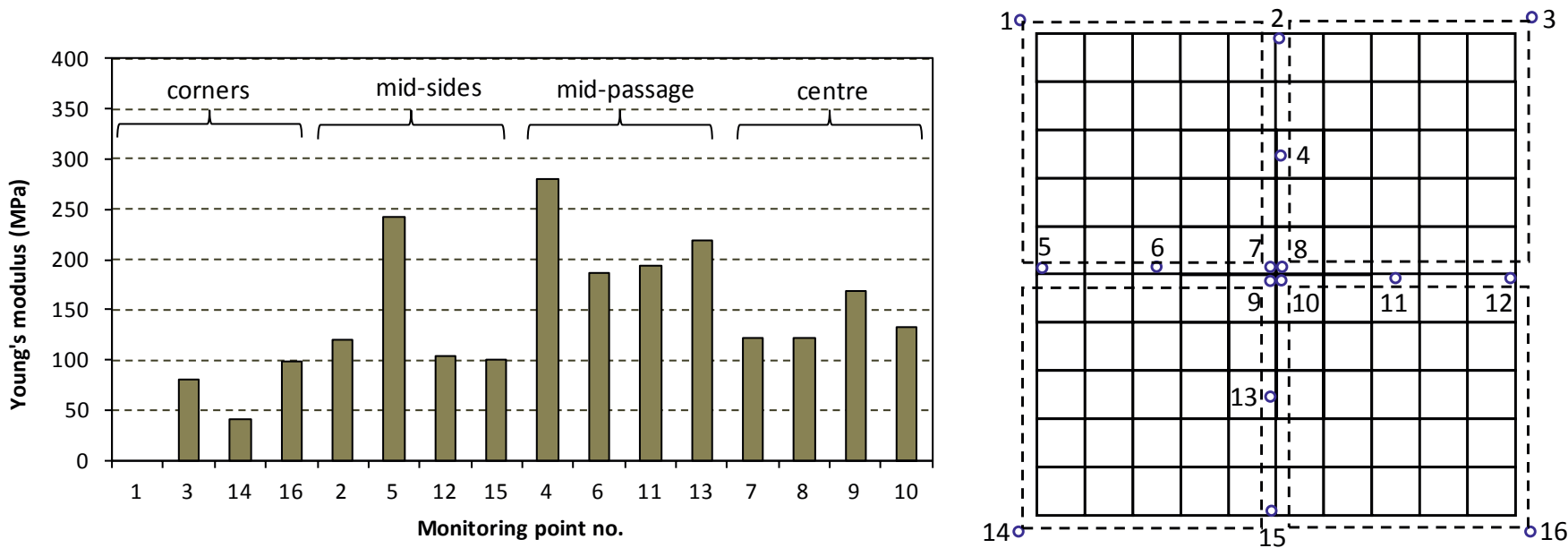

Note:Point 1 was damaged.

Fig. 10. Distribution of calculated stiffness at Pier 26.
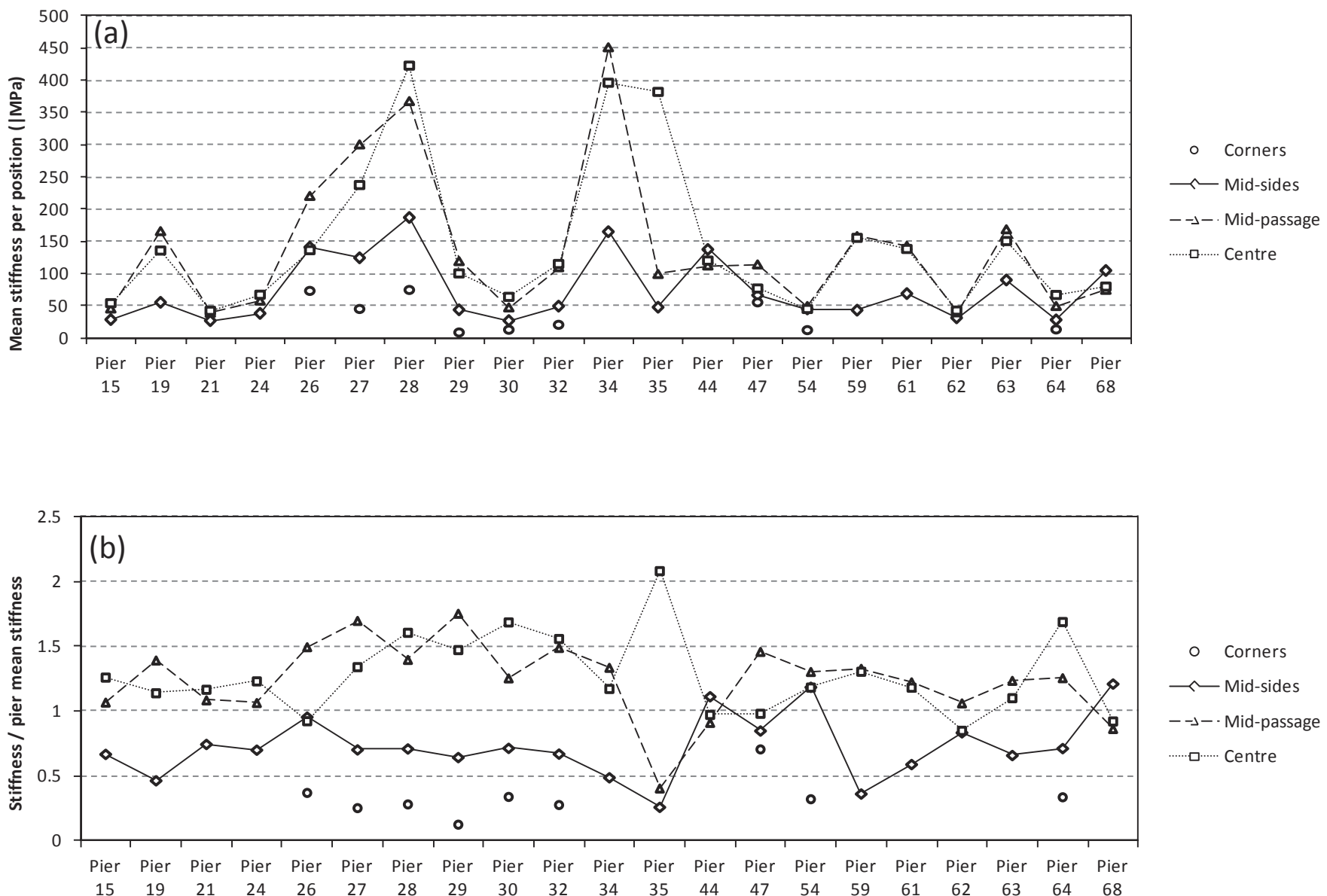

Fig. 11. Normalized stiffness values at mid-side, mid-passage, centre and corner positions of surcharged piers along the viaduct.

owing to the preloading of the soil. Figure 14 presents the ratio of the average rebound stiffness to the average virgin stiffness for the test locations for which rebound data are available. Excluding the three highest values, which are thought to be outliers, the mean rebound stiffness amounted to 3.3 times the virgin stiffness. The outliers are attributable to very small amounts of rebound measured, rather than unusually large virgin settlements.

\section{Discussion}

\section{Back-calculated profile stiffness values}

Soil stiffness values for foundation design on the dolomites in South Africa have often been determined from plate load tests on the various materials forming the profile. Given the state of knowledge at the time, this approach was reasonable. For example, Ward 
Table 2. Young's moduli back-calculated from surcharge trials

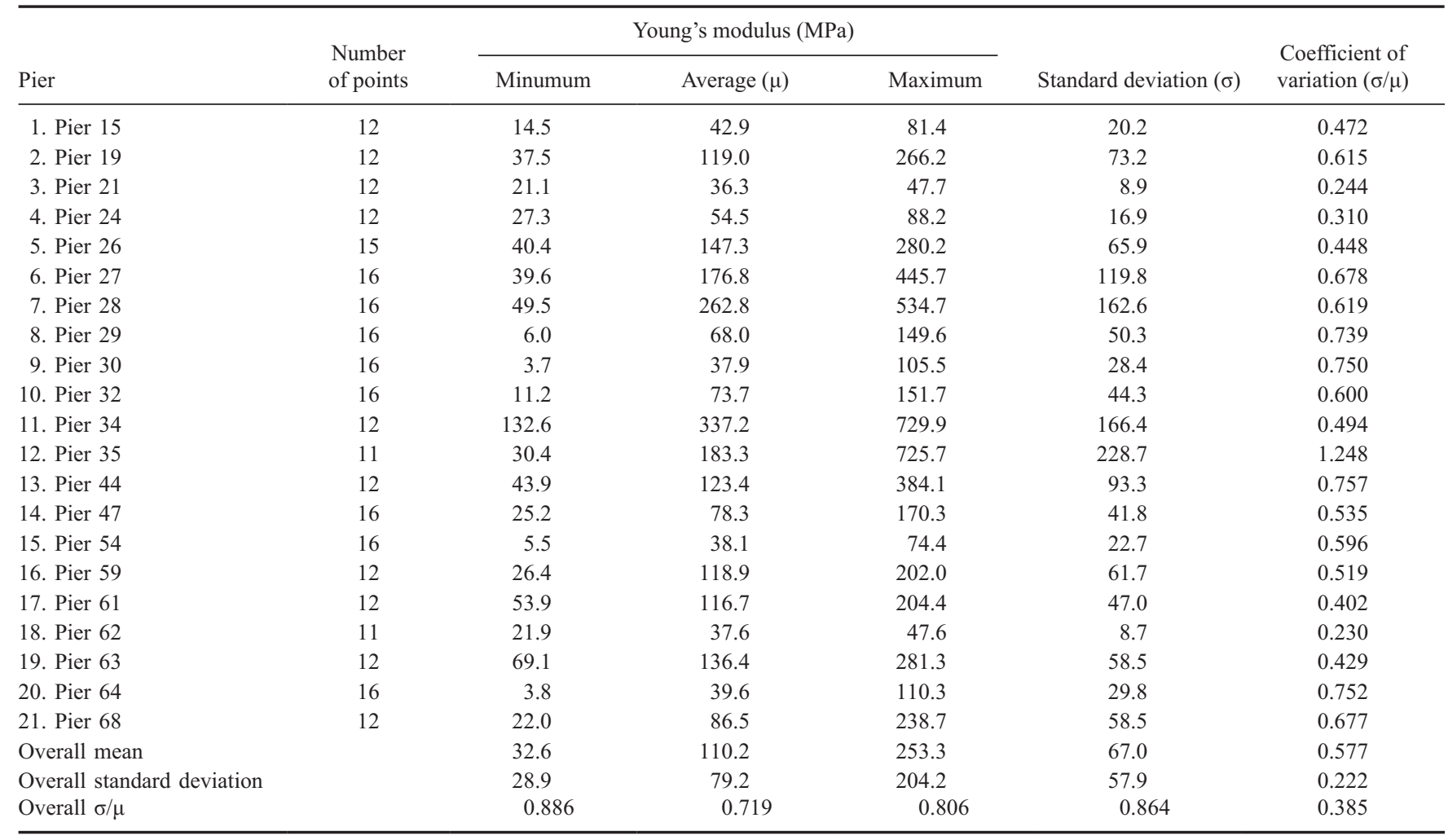

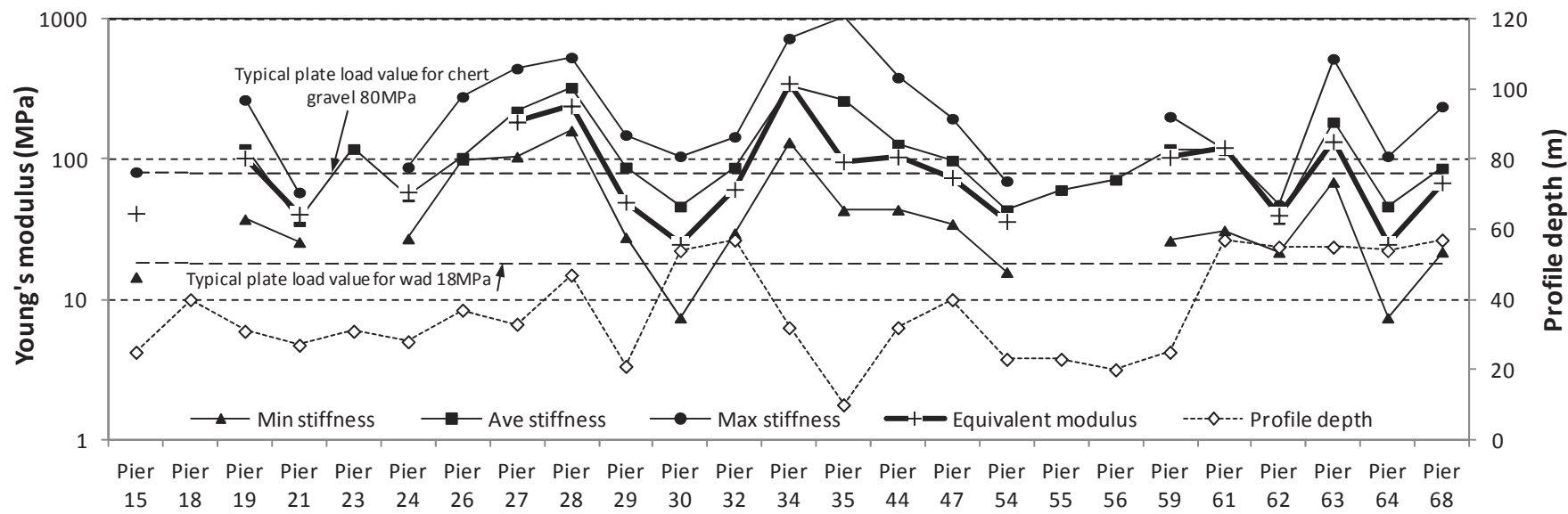

Fig. 12. Average profile stiffness and depth to bedrock along viaduct alignment, also showing typical plate load moduli for wad and chert gravels from Wagener (1982).

et al. (1968) reported agreement between stiffness moduli from a large-scale surcharge trial and plate load tests. Comparing the stiffness values of various dolomitic residuum materials from the literature (Table 1) with those back-calculated from the surcharge trials (Table 2), the mass stiffness of the profile was generally significantly higher than that of its components. This provided justification for the use of higher stiffness values in the design of the Gautrain viaduct than would previously have been used in the absence of large-scale surcharge trial data.

Equivalent stiffness moduli for each surcharge trial were calculated using the average settlement over the entire surcharge area, the average applied stress, and assuming a flexible surcharge load over a finite profile depth. A Poisson ratio of 0.3 was assumed, whereas no Poisson ratio was used in the stiffness calculations first presented. The equivalent moduli are plotted in Figure 12. These values are slightly lower than the average stiffness moduli determined using the simplified method but generally correspond well. Deviations occur because, for many of the surcharge trials, corner settlement values are not available. (The corners usually settled more, significantly affecting the mean settlement values.)

\section{Theoretical versus observed settlement patterns}

A typical set of parameters, representative of some surcharge trials, is as follows: loaded area $20 \mathrm{~m} \times 20 \mathrm{~m}$; surcharge pressure $200 \mathrm{kPa}$; average Young's modulus $100 \mathrm{MPa}$; estimated Poisson ratio 0.3 ; depth to bedrock $30 \mathrm{~m}$. 

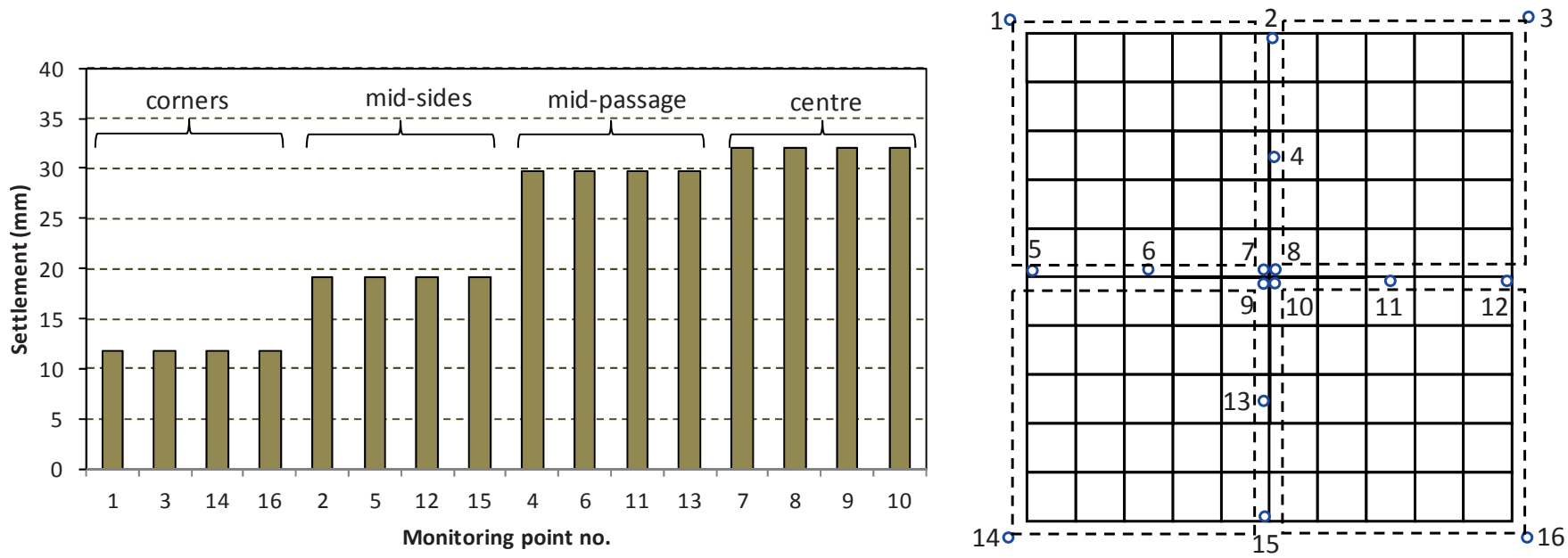

Fig. 15. Distribution of settlements resulting in a back-calculated stiffness of $100 \mathrm{MPa}$.

edges could perhaps be a consequence of higher stresses being exerted there because of the rigid behaviour of the surcharge stacks. Despite not being structurally connected, the configuration of blocks forming the surcharge stacks (see Fig. 3b) would not have been perfectly flexible. The observed settlement pattern therefore appears to be a consequence of both increasing soil stiffness with depth (at least to a certain depth) and the relative rigidity of the surcharge stacks. Doing away with the passage between surcharge quadrants from the third trial onwards would have increased the overall rigidity of the surcharge stack, probably resulting in it behaving more like a rigid foundation.

The above observations have implications for the back-analysis of stiffness values from settlements. The simple method for the backanalysis of stiffness assumed a homogeneous, isotropic, linear elastic subgrade, loaded by a perfectly flexible surcharge. This approach stems from a design office environment where structural engineers requested linear elastic parameters, necessitating that conservative stiffness values had to be determined in a short space of time.

More accurate stiffness may be calculated by assuming the surcharge to possess some rigidity and by taking into account nonhomogeneity (increase in stiffness with depth up to a point), as well as stiffness anisotropy and non-linearity (i.e. a modern constitutive soil model). Should this be done, higher stresses at the corners and edges, given the same settlements, will result in higher stiffness values being calculated there, whereas somewhat lower stiffnesses will be calculated near the centre, reducing the scatter in stiffness data presented in Figure 11. A comprehensive analysis would, however, require subsurface settlement data and is outside the scope of this paper.

\section{Variation in back-calculated stiffness values}

Reasons for the large variation in settlement data were investigated by excavating a number of test pits (to $c .3 \mathrm{~m}$ depth) on the footprints of some surcharged areas after removal of the load. Materials encountered varied widely from relatively soft manganese-rich sandy clayey silts, reworked residual syenite, densely packed chert gravels and boulders, and naturally transported materials to fills of various origins and consistencies.

The highest stresses from the surcharge occur immediately below the surcharge but reduce as stresses distribute with depth. As stress is distributed with depth, stiffer zones would tend to support most of the load, as a result of arching, probably leaving most of the compressible zones virtually unloaded. The behaviour of the surcharge is therefore unlikely to be affected much by soft inclusions (e.g. pockets of wad or cavities) at depth within a matrix of stiffer material (chert boulders and gravels). However, at the surface this stress distribution had not yet occurred, so that the presence of near-surface zones of various consistencies is more likely to affect surcharge settlement. This variation in consistency of near-surface materials observed during the test pit investigation is thought to be the main reason for the scatter in stiffness data. The dolomite residuum is extremely heterogeneous.

As alluded to above, the stiffness variation is also to some extent likely to have been a consequence of the method of backanalysis, but the evidence suggests that this is of secondary importance relative to the variability in stiffness of the near-surface materials.

Little or no correlation between stiffness and depth to bedrock was found (Fig. 13).

\section{Designing for differential settlement on dolomite residuum}

The highly variable nature of the near-surface material and the observed associated settlement (see Fig. 8) suggest that it appears reasonable and conservative to recommend that differential settlements on similar soil profiles be estimated as equal to the maximum calculated surface settlement. This can be compared against the usual practice to typically design for between one-third and two-thirds of this value, depending on the soil profile (Simons \& Menzies 2001).

\section{Conclusions}

The design of the Gautrain viaduct through Centurion required stiffness parameters to be determined, representative of the underlying soil profile and the loading imposed by the viaduct. The residual dolomite profile underlying the line is extremely heterogeneous and impossible to characterize in a representative way using routine (e.g. plate load or laboratory) tests. A series of large-scale surcharge trials, designed to exert loads similar to that imposed by the viaduct, was carried out from which representative mass stiffness values could be calculated. The mean stiffness values thus determined corresponded well to equivalent moduli calculated from elastic solutions based on average surcharge settlements. 
The settlement data were found to be highly variable. The variability is ascribed to the surcharge being sensitive to the variations in the consistency of the heterogeneous near-surface materials. As stress distributes with depth, stiffer materials would tend to carry most load so that the behaviour of the surcharge would become less sensitive to the presence of compressible pockets at depth. Compressible materials at depth will not be loaded, or will be loaded only lightly.

A secondary contributor to settlement variability results from the mass-behaviour of the surcharge stacks. Despite being able to settle differentially, it appears that the surcharge exerts a load distribution-in-plan similar to a load with rigidity, with the perimeter being more heavily loaded and subsequently settling more than the centre. This is contrary to the initial expectation of a flexible surcharge, but could also be a consequence of nonhomogeneity in stiffness with depth or stiffness anisotropy. The surcharge blocks were expected to behave as a flexible load as they were free to move independently. This has implications for the back-calculation of stiffness from the settlement data because the load applied by the surcharge at the surface is not uniform in plan.

Improvements in back-calculating stiffnesses from the settlement data can be made by taking into account non-homogeneity of stiffness with depth and non-linear soil stiffness. Calibration of such models requires settlement data at various depths. The effects of soil yield are considered to be of secondary importance.

The mass stiffness values back-calculated from the results of the surcharge trials were found to be significantly higher than the values quoted in the literature for components of a residual dolomite profile, typically chert gravels and wad (see Fig. 12). Values in the literature are mostly based on plate load test results. This meant that less conservative stiffness moduli could be used in the design of the foundations of the Gautrain viaduct, resulting in a more economical design.

It is recommended that the potential differential foundation settlement be estimated as equal to the total expected settlement.
Acknowledgements. The author wishes to thank the Gauteng Province and Bombela CJV for permission to publish the information contained in this paper. The author also wishes to express his gratitude to C. Clayton for his support in drafting this paper.

\section{References}

Bombela CJV 2007. Assumptions Report, Detail Design 6A, Foundation Design Part 1 of 2. Bombela CJV, Report CJV-L05-CDE-2664 0805.

Boswell, L.F. \& ScotT, C.R. 1975. A flexible circular plate on a heterogeneous elastic half-space: Influence coefficients for contact stress and settlement. Géotechnique, 25, 604-610.

ButTrick, D.B. 1986. Wad and ferroan soil developed in the dolomitic area south of Pretoria. MSc thesis, University of Pretoria.

CARrier, W.D. \& Christian, J.T. 1973. Rigid circular plate resting on a nonhomogeneous elastic half-space. Géotechnique, 23, 67-84.

Gibson, R.E. 1967. Some results concerning displacements and stresses in a non-homogeneous elastic half-space. Géotechnique, 17, 58-67.

Gibson, R.E. 1974. The analytical method in soil mechanics. Géotechnique, 24, 115-140.

Jardine, R.J., Potts, D.M., Fourie, A.B. \& Burland, J.B. 1986. Studies on the influence of non-linear stress-strain characteristics in soil-structure interaction. Géotechnique, 36, 377-396.

Johnson, M.R., Anhaeusser, C.R. \& Thomas, R.J. 2006. The Geology of South Africa. Geological Society of South Africa and Council for Geoscience, Pretoria.

Poulos, H.G. \& Davis, E.H. 1974. Elastic Solutions for Soil and Rock Mechanics. Wiley, New York.

RodriguES J.S. 1975. The development and application of a finite element program for the solution of geotechnical problems. $\mathrm{PhD}$ Thesis, University of Surrey, Guildford.

Simons, N.E. \& Menzies, B.K. 2001. A Short Course on Foundation Engineering, 2nd edn. Thomas Telford, London.

Tosen, R., Storry, R.B. \& Hoeben, S. 2009. Borehole radar cavity and discontinuity assessment in dolomite for Gautrain. In: Proceedings of ISRM Regional Symposium, Eurock 2009, Dubrovnik. Balkema, Rotterdam, 387-392.

WAGENER, F. von M. 1982. Engineering construction on dolomite. PhD thesis, University of Natal.

Ward, W.H., Burland, J.B. \& Gallois, R.W. 1968. Geotechnical assessment of a site at Mundford, Norfolk, for a large proton accelerator. Géotechnique, 18, 399-431. 